\title{
SISTEMA DE ESPAÇOS LIVRES NAS CIDADES BRASILEIRAS - UM DEBATE CONCEITUAL
}

\author{
OPEN SPACES SYSTEM IN THE BRAZILIAN CITIES - A CONCEPTUAL DEBATE
}

\section{Mônica Bahia Schlee}

Urbanista e arquiteta-paisagista, doutoranda do PROARQ - FAU-UFRJ, com mestrado em Estruturais Ambientais Urbanas pela FAUUSP e Arquitetuta da Paisagem pela Penn State University.

e-mails:monbasch@gmail.com/mbschlee@rio.ri.gov.br

\section{Maria Julieta Nunes}

Arquiteta e urbanista, professora adjunta da FAU-UFRJ, com doutorado em Comunicação e Cultura pela ECO-UFRJ.

e-mail: mariajulieta@globo.com

\section{Andrea Queiroz Rego}

Arquiteta e urbanista, professora adjunta da Universidade Gama Filho, com doutorado em Urbanismo pelo PROURB-FAU-UFRJ.

e-mail: aqrego@yahoo.com.br

\section{Paulo Rheingantz}

Arquiteto e urbanista, professor associado da FAU-UFRJ, docente e pesquisador do PROARQ - FAU UFRJ, com doutorado pela COPPE-UFRJ.

e-mail: parheingantz@gmail.com

\section{Maria Ângela Dias}

Arquiteta e urbanista, professora associada da FAU-UFRJ e pesquisadora do PROARQ - FAU-UFRJ, com doutorado pela COPPE-UFRJ.

e-mail:magelias@uol.com.br

\section{Vera Regina Tângari}

Arquiteta e urbanista, professora adjunta da FAU-UFRJ e docente e pesquisadora do PROARQ - FAUUFRJ, com doutorado em Estruturais Ambientais Urbanas pela FAUUSP.

e-mail:vtangari@uol.com.br

\section{RESUMO}

Este artigo se propõe a construir um quadro de referências para a compreensão dos sistemas de espaços livres de edificação aplicados a diversas escalas de análise. Neste artigo são enfocados alguns conceitos iniciais, considerados fundamentais para a compreensão do tema em questão: "território", "paisagem", "ambiente", "sistema" e "espaço", envolvendo contribuições de diversos campos do conhecimento. O recorte proposto buscou relacionar os diversos significados dos conceitos, criticamente analisados, com vistas à construção de um arcabouço teórico transdisciplinar. Reflete o esforço de síntese conceitual que servirá de base para nortear futuras investigações e busca oferecer uma perspectiva contemporânea do assunto, possibilitando configurar um panorama de debate sobre o conteúdo sociocultural e a forma dos sistemas de espaços livres e de sua relação com a paisagem brasileira.

Palavras-chave: Espaços livres, paisagem, território. 


\section{ABSTRACT}

This paper presents a theoretical framework for the comprehension of the open spaces systems, referred to the non-built environment, as applied to different spatial scales. In this paper, some concepts were selected by the authors to be discussed: territory, landscape, environment, system and space, gathering contributions of different scientific fields. The goal is to relate the diverse meanings of the concepts, and analyse them critically, in order to construct a transdisciplinary theoretical framework. It reflects a conceptual synthesis effort and seeks to offer a contemporary approach about the subject, enabling an enlarged debate about the socio-cultural contempt and the formal configuration of the open spaces systems and their relationship with the brazilian landscape.

Key words: Open spaces system, landscape, territory.

\section{INTRODUÇÃO}

O Grupo Sistema de Espaços Livres nas Cidades Brasileiras - Rio de Janeiro (SEL-RJ) se dedica a estudar os sistemas de espaços livres de edificação, seus padrões espaciais e seu papel na estruturação, transformação e dinâmica da paisagem. $\bigcirc$ conceito "espaços livres de edificação", utilizado nesse trabalho, foi abordado inicialmente no Brasil, a partir da década de 1970, principalmente por Miranda Magnoli, tendo sido a base de construção argumentativa de sua produção científica na Faculdade de Arquitetura e Urbanismo da USP (MAGNOLI, 2006, p. 143-173).

Para tanto, o grupo SEL-RJ propõe uma análise crítica sobre as condições de diversidade e as contradições que se expressam nos espaços livres, abordando aspectos sobre a fundamentação conceitual, a morfologia, a escala, a hierarquia, os atributos sociais e culturais e as formas de apropriação desses espaços no tempo. Esta análise se apóia em abordagens transdisciplinares, abrangendo conceitos da arquitetura e do urbanismo, da ecologia da paisagem, da geografia, da psicologia e da antropologia.

A fundamentação conceitual utilizada considera a diversidade do ambiente natural e cultural brasileiro como resultado dos fatores biofísicos, das ações humanas e da combinação de ambos, como definido por Bertrand (BERTRAND, 1971), ratificado pela Convenção Européia da Paisagem (CONSELHO DA EUROPA, 2000) e descrito por Aziz Ab'Saber (AB'SABER, 2003), ao discorrer, com propriedade, sobre os domínios paisagísticos brasileiros. Iniqüidades na distribuição da terra e da renda, nos contextos urbanos e nos contextos rurais, levaram a conflitos e contradições que se refletem claramente na distribuição, na apropriação e no tratamento dos espaços livres e em sua relação com os espaços edificados.

A partir da visão de Cosgrove (1998), podemos afirmar que o território brasileiro abriga diversas culturas, refletidas em uma ou mais culturas dominantes, cada uma delas exercendo sua própria expressão na paisagem das áreas urbanizadas e nãourbanizadas. Nesse contexto, os espaços livres exprimem as diversas associações, os conflitos e as contradições inerentes às paisagens brasileiras, relacionadas aos aspectos sociais e culturais, tanto regionais quanto locais e à sua interação com as formas construídas. Com base nessas premissas, considera-se a compreensão das características regionais fundamental para promover mudanças no planejamento e no desenho dos espaços livres brasileiros. 
As seguintes questões foram inicialmente colocadas para embasar e orientar possíveis desdobramentos da pesquisa:

Como se definem os diferentes sistemas de espaços livres e qual a contribuição de cada um desses diferentes sistemas para a constituição da esfera pública contemporânea nas diversas realidades brasileiras?

Quais as contradições percebidas na relação: ocupação x território; planejamento x gestão; suporte físico-ambiental x paisagem cultural?

Como a questão da escala e os níveis hierárquicos afetam o estudo dos sistemas de espaços livres?

Quais os diferentes papéis e potencialidades dos sistemas de espaços livres no tempo?

Quais as principais formas de apropriação e quais as relações entre as diferentes práticas espaciais e sociais dos sistemas de espaços livres?

Quais as potencialidades ecológicas do sistema de espaços livres para conservar e regenerar os recursos naturais ainda existentes?

Como articular o modo coletivo de gestão e o modo individual de apropriação e reapropriação dos sistemas de espaços livres?

Não se pretende responder a essas questões no âmbito deste trabalho, mas as referenciar como ponto de partida e motivação às discussões e embates conceituais descritos a seguir. Neste artigo, destacamos a importância e a aplicação dos conceitos enumerados à análise dos diferentes objetos de pesquisa do grupo, considerando-os como chaves de leitura e análise. Objetivamos também ampliar a proposição conceitual proposta em trabalho anterior pela equipe do Projeto de Pesquisa Quadro de Paisagismo no Brasil, do Laboratório da Paisagem da FAUUSP (HIJIOKA et al, 2007).

\title{
1 - AS QUESTÕES INICIAIS E OS EMBATES CONCEITUAIS
}

\author{
"Um produto ideológico faz parte de uma realidade \\ (natural ou social) como todo corpo físico, instrumento de pro- \\ dução ou produto de consumo; mas, ao contrário destes, ele \\ também reflete e refrata uma outra realidade que the é exterior." \\ Mikhail Bakhtin, 1997
}

Conceitos têm a propriedade de orientar certas formas e nuances dos diversos "olhares" sobre uma mesma realidade, que é inapreensível em toda a sua completude. Como os conceitos estabelecem epistemologias condizentes com os posicionamentos filosóficos, em contínua transformação, eles nos auxiliam a enxergar por esses diversos "olhares" e a compreender a realidade em suas diferentes manifestações.

A tomada de consciência do homem como sujeito, protagonista da história pela consciência de si, contribuiu para a febre antropocentrista que, durante um longo tempo, embasou o surgimento de diferentes modos de conceituar o mundo externo. Este artigo não tem a pretensão de esgotar os enfoques ou derrubar os conceitos forjados no tempo, substituindo-os por visões mais atualizadas. Por entendermos que os novos modos de 
olhar concorrem e mesmo complementam os anteriores, evitaremos buscar noções de sentido único. Nosso interesse é, sobretudo, explicitar as abrangências, convergências e afastamentos no intuito de colher, entre conceitos utilizados em campos disciplinares diferentes, aqueles que mais auxiliam na aplicação aos objetos que estamos estudando: os sistemas de espaços livres, públicos e privados, e sua relação com a paisagem.

Nesse sentido, os conceitos' surgem como ferramentas para identificar, descrever, qualificar e relacionar os diferentes elementos e aspectos da realidade, auxiliando-nos em sua compreensão, mas resultam, por outro lado, do grau de conhecimento acumulado até o momento de sua formulação. Enquanto representação são dinâmicos, variam culturalmente e ao longo do tempo e só podem ser entendidos em uma perspectiva histórica. Em outras palavras, os conceitos são historicamente condicionados, o que não significa, necessariamente, que venham a ser superados, mas são "inacabados", já que refletem compreensões limitadas ao grau de conhecimento do momento em que foram formulados e incorporam construções culturais as quais se alteram no tempo. Por isso justifica-se esse exercício de contextualização do quadro de referências a fundamentar cada conceito, para entendermos o que cada um pode representar atualmente.

$\mathrm{Na}$ formulação dos conceitos a seguir discutidos estão contidas expressões de diferentes dimensões ideológicas, uma vez que os conceitos produzem significados relativos ao sentido que adquirem no contexto de sistemas determinados de pensamento (GENRO FILHO, 1986). Tendo como objeto de estudo a análise dos sistemas de espaços livres, o encaminhamento da presente discussão conceitual parte das definições mais abrangentes, relativas a território, paisagem e ambiente, às mais centrais ao nosso foco: sistema e espaço.

\section{2 - TERRITÓRIO}

Durante o século XX, diversos campos disciplinares procuraram estudar a definição desse conceito, de suas propriedades e dos processos que definem suas múltiplas relações com o espaço, a cultura e a sociedade. Percebemos, nas leituras realizadas, abordagens diferenciadas para a definição de território, que devem ser analisadas complementarmente, pois se aplicam de forma integrada às dimensões de análise propostas. Essas abordagens incluem as dimensões com enfoque físico-espacial, geopolítico e socioeconômico, e as dimensões com enfoque simbólico, subjetivo e perceptivo.

\section{1 - Enfoques físicoespaciais, geopolíticos e socioeconômicos}

Conforme descrito por Souza, historicamente, o conceito de território foi pensado, definido e delimitado no campo da geografia como expressão de poder sobre o espaço e seus recursos, de manutenção de um modo de vida, de uma identidade ou liberdade de ação, atrelando-se a condições de dominação-influência-apropriação (SOUZA, 1995). Esse autor argumenta que territórios são construídos e desconstruídos nas mais diversas escalas espaciais e temporais e configuram "um complexo campo de forças, teias ou redes de relações sociais projetadas no espaço" (SOUZA, 1995, p. 86-87). Na 
mesma linha, Gomes define território como uma parcela do espaço "utilizada como forma de expressão e exercício de controle sobre outrem", pela "imposição de regras de acesso, de circulação, da normatização de usos, atitudes e comportamentos" (GOMES, 2002, p. 12).

Nesse sentido, auxiliam as concepções contemporâneas que, de acordo com Claval, a partir do pós-guerra, surgem entre geógrafos, com aportes de biólogos e etnólogos, ultrapassando as limitações do conceito de espaço, no sentido do território (CLAVAL, 1999). Raffestin, um de seus maiores difusores, entende ser "essencial compreender que o espaço é anterior ao território. O território se forma a partir do espaço, é o resultado de uma ação conduzida por um ator sintagmático (ator que realiza um programa) em qualquer nível. Ao se apropriar de um espaço, concreta ou abstratamente (...) o ator 'territorializa' o espaço" (RAFFESTIN, 1993, p. 143). É o "processo de territorialização" que está na base desse pensamento.

Corrêa recorre ao conceito de "processo espacial" como "um conjunto de forças atuantes ao longo do tempo, postas em ação pelos diversos agentes modeladores (do espaço), e que permitem localizações e relocalizações de atividades e da população na cidade", ou seja, transformações espaciais permanentes, que terminam por estabelecer vínculos, neste caso, socioeconômicos, entre lugares em permanente interação (CORRÊA, 1989, p. 35).

Mas o território inclui, ainda, a construção de laços afetivos ligando espaço vivido $x$ trajetória pessoal/familiar x construção de "mundo comum", necessariamente tecidos no tempo, e que convergem no sentido de um "enraizamento", uma mistura das trajetórias pessoais, sociais e espaciais, dadas por um mesmo espaço "vivido". Retomando Raffestin, "o território se apóia no espaço, mas não é o espaço. É uma produção a partir do espaço. Ora, a produção, por causa de todas as relações que envolve, se inscreve no campo do poder (...)" (1993, p. 144). A noção de território introduz, assim, a dimensão simbólica, que se situa na base dessa construção.

Destaca-se, aqui, o trabalho pioneiro de Michel Foucault, o qual funda uma pródiga vertente sobre a dimensão simbólica do espaço vinculada ao poder, e avança na idéia de haver uma "subjetividade" que o atravessa necessariamente, gerada pelas intervenções cotidianas de seus moradores, individual ou coletivamente, deixando marcas objetivas embebidas de significados subjetivos, que embutem estratégias de dominação, no contexto da sociedade de classes (FOUCAULT, 1979).

Ampliando-se a conceituação segundo uma visão que incorpora aspectos produtivos, destaca-se a definição de Milton Santos, para quem "o território não é apenas um conjunto de formas naturais, mas um conjunto de sistemas naturais e artificiais, junto com as pessoas, as instituições e as empresas que abriga. O território [...] deve ser considerado em suas divisões jurídico políticas, suas heranças históricas, seu atual conteúdo econômico, financeiro, fiscal e normativo. É desse modo que ele constitui [...] um quadro da vida social onde tudo é interdependente" (SANTOS, 2002, p. 84). Esse autor considera, ainda, que o território assume um papel vital na articulação de poderes nesse momento histórico no qual se multiplicam as trocas, pois ele "permite uma visão não 
fragmentada e unificada dos diversos processos sociais, econômicos e políticos", ao mesmo tempo em que admite: "lugares e regiões tornam se tão fundamentais para explicar a produção, o comércio, a política, que se tornou impossível deixar de reconhecer o seu papel na elaboração do destino dos países e do mundo." (SANTOS, 2002, p. 99, 101)

\section{2 - Enfoques simbólicos, subjetivos e perceptivos}

Para o presente enfoque, são úteis os vínculos que alguns autores tecem entre território e identidade. Claval mostra a gênese da idéia de "identidade", a originar-se na psicologia, no contexto dos estudos sobre a constituição do sujeito, em sua acepção mais relacional, pondo em relevo a idéia de "alteridade": a construção da identidade do indivíduo como necessária diferenciação, tendo em vista a existência de "outros", ou de "alteridades" lançadas sobre si. É por estar confrontado com forças da alteridade que os indivíduos e coletividades desenvolvem a necessidade de diferenciar-se, identificar-se (CLAVAL, 1999).

Esse raciocínio foi trazido para um plano mais amplo: identidade não apenas no plano individual, mas também no coletivo, e sua construção toma a dimensão espacial como importante componente. Ao "construir seu cotidiano no cotidiano da cidade'", como na feliz expressão de Carlos, os grupos sociais misturam suas trajetórias nos processos espaciais em curso, laços afetivos complexos, provenientes de "sua história misturada com a daquele lugar". Como parte desse processo, apropriam-se de elementos espaciais e transformam-nos, deixando suas marcas no espaço vivido (CARLOS, 1994, p. 11).

A abordagem psicossocial, de acordo com Fischer, define o "território como campo topológico", um recorte "do espaço físico em zonas subjetivas delimitadas pela qualidade das relações" nele e "com ele estabelecidas". O conceito de território corresponde, segundo o autor, a um espaço físico delimitado, com significados psicológicos e culturais, organizado para uma atividade definida, cuja configuração se estabelece a partir das funções que acolhe. O território é um "lugar socializado" onde suas "características físicas e os aspectos culturais que the são atribuídos se combinam em um único sistema" (FISCHER, 1994, p. 23-24).

O território ou espaço social ao mesmo tempo inclui e exclui, é objeto de mecanismos de controle e subversão. Gera raízes, suscita vínculos, afinidades, relações de pertencimento e identidade (SOUZA, 1995; GOMES, 2002). Estabelece-se com base em regras e é delimitado por fronteiras que fixam seus limites materiais e simbólicos. Nesse sentido, o conceito de território nos remete diretamente ao de territorialidade, em que, tanto nas análises de Gomes (2002) como na de Fischer (1994) essa propriedade é vista como o conjunto de estratégias e ações utilizadas para demonstrar, manter e reforçar o poder sobre o espaço. Segundo essa posição, as características morfológicas do espaço físico (sua disposição, localização e ordenação) são confrontadas com o conteúdo e os processos comportamentais dos grupos sociais que o ocupam.

Para Fischer, a dominância territorial pressupõe a construção de zonas de influência associadas ao controle sobre o espaço. Segundo o autor, "os sinais desta influência podem ser variados", pois a idéia de território implica na personalização do lugar com 
a ajuda de marcações e elementos de apropriação, sendo resultado da organização social que inscreve, no ambiente, regras e usos culturais de um determinado grupo ou sociedade. Uma outra característica dos territórios é sua delimitação por meio de fronteiras, materiais e simbólicas. "Fronteiras e marcadores articulam-se em códigos que informam sobre a natureza" e as características de um determinado ambiente, e "informam sobre o grau de personalização de um lugar", indicando o valor do território como aspecto inerente às condições sociais em que é utilizado (FISCHER, 1994, p. 26-27).

Uma diferenciação importante entre as concepções em relação ao conceito de território, utilizadas, de um lado, pela geografia física e, de outro, pela geografia cultural e a psicologia ambiental, diz respeito diretamente aos seus limites. Enquanto a geografia física os define como precisos, em que as fronteiras não apresentam transições, a geografia cultural amplia essa visão, ao considerar o território como espaço político com limites fluidos, instáveis, com nuances e superposições associadas ao simbolismo que thes são atribuídos (ALTMAN, 1975; SOUZA, 1995; GOMES, 2002). Na visão de Souza, nem mesmo os limites políticos são imutáveis, visto estes poderem ser alterados pela força. Altman (1975) distinguiu dois tipos de territórios de acordo com o nível de domínio, influência e controle social: os territórios primários, geralmente privados, nos quais o domínio e o controle são claramente estabelecidos por limites definidos, e os territórios secundários, que não se configuram como completamente privados nem totalmente públicos, correspondendo aos enclaves criados por grupos e regidos por regras, rituais e códigos de condutas comuns a esses grupos. Esses territórios configurariam zonas de sombreamento e superposição entre as esferas pública e privada.

Finalmente, a partir da interseção entre as abordagens descritas acima, especificamos, aqui, a discussão sobre esse conceito, que tem norteado os estudos sobre nossos objetos de pesquisa, ao definirmos território como sendo uma construção social, a incorporar os processos econômicos e produtivos, definir estratégias de dominação sobre o espaço e seus recursos e manifestar-se sobre uma base física, por meio de múltiplas apropriações, individuais e coletivas, delimitando marcas e marcos de identidade cultural.

Pretendemos incorporar a essa definição os rebatimentos mais sensíveis que perpassam diferentes escalas, tempos e tipos de identificação e identidade cultural, de forma material-objetiva e imaterial-perceptiva, desde a análise dos sistemas de espaços na escala da região até as situações mais locais, nos estudos sobre como os indivíduos e grupos escolhem, cunham e determinam seus "territórios" e "lugares". Ao aplicarmos essa conceituação fundada nas diversas dimensões descritas e em suas convergências, rebatemos aos nossos estudos iniciais, que alcançam desde escalas de gestão territorial municipal e regional até os aspectos vinculados à identificação e qualificação de fronteiras entre sistemas de espaços livres de edificação, os quais transitam entre as esferas pública e privada e entre as formas de ocupação urbana e sua matriz de suporte natural, caracterizada por fragmentos ambientais mais ou menos frágeis. 


\section{3 - PAISAGEM}

conceito de paisagem admite múltiplas significações e significados, apropriados e referenciados por diversas disciplinas, cuja base de conhecimento se ampliou a partir do aumento de intensidade, complexidade e abrangência da intervenção humana sobre a superfície da Terra, segundo nos descreve Miranda Magnoli (MAGNOLI, 2006). Para alguns autores, ainda hoje, o conceito de paisagem está associado a uma extensão de território ao alcance da vista, formada pelo conjunto de elementos e formas naturais construídos pelo ser humano. Esses autores, entre os quais Carlos (1994), definem paisagem como o "imediatamente visível", aquilo que somos capazes de apreender pelo olhar, em uma unidade visual. A noção de paisagem, no entanto, implica a apreensão de uma porção do espaço em três dimensões, produto da interface entre natureza e cultura, e, conseqüentemente, abrange múltiplos aspectos e sentidos, além do visual.

Magnoli enfatiza a importância de entender-se as diferentes matrizes, situações e níveis de antropização que se observam, contemporaneamente, e as diferentes abordagens do conceito de paisagem, variável em escala, em percepção e em dimensão temporal. ${ }^{2}$

Essa visão reforça o pensamento segundo o qual não há paisagem sem transformação e não há natureza sem a ação humana. A paisagem é, portanto, um produto profundamente impregnado de cultura, que resulta de processos de alteração contínuos, ditados por fatos biofísicos, sociais e econômicos, portanto também políticos, rebatidos nas formas de ocupação e gestão do território. Ou como descreve Ab'Saber: "paisagem é sempre uma herança,... herança de processos fisiográficos e biológicos, e patrimônio coletivo dos povos que historicamente as herdaram como território de atuação de suas comunidades." (AB'SABER, 2003, p. 9)

Nesse sentido, destacamos também a definição formulada por Silvio Macedo: "a paisagem pode ser considerada como um produto e como um sistema. Como um produto porque resulta de um processo social de ocupação e de gestão de determinado território. Como um sistema, na medida em que a partir de qualquer ação sobre ela impressa, com certeza haverá reação correspondente, que equivale ao surgimento de uma alteração morfológica parcial ou total." (MACEDO,1999, p. 11)

A partir dessa visão, podemos atribuir ao conceito de "paisagem" diversas dimensões de análise e interpretação, utilizadas pelos diversos campos de conhecimento voltados ao seu estudo, conhecimento e intervenção. Essas dimensões podem ser subdivididas em duas vertentes, a partir de descrição feita por Maria Angela Faggin P. Leite: a vertente que relaciona a paisagem à sua essência física, material, objetiva, categorizável, e a vertente que relaciona a paisagem à sua essência simbólica, à sua experimentação e criação individual ou coletiva (LEITE, 1992, p. 45).

Na primeira vertente, podemos incluir a dimensão morfológica, funcional e espacial, e, na segunda, a dimensão histórica e simbólica, conforme descritas em seguida: (a) dimensão morfológica, na qual a paisagem é traduzida como um conjunto de configurações formais, derivadas da natureza e da ação humana ${ }^{3}$; (b) dimensão funcional, 
relativa à organização, porque suas partes guardam relações entre si; (c) dimensão histórica, na medida em que é produto das transformações ocorridas ao longo do tempo; (d) dimensão simbólica, pois a paisagem carrega significados que expressam valores, crenças, mitos e utopias; e (e) dimensão dinâmica, a relacionar os padrões espaciais aos processos que lhes deram origem. Essas dimensões não são excludentes, pelo contrário, interagem e explicitam os processos os quais são responsáveis pelas transformações e configurações refletidas pelas e nas paisagens existentes.

\section{1 - Paisagem como essência física, material, objetiva e categorizável}

A paisagem foi inicialmente percebida como a expressão materializada das relações do homem com a natureza em uma determinada porção do espaço (CLAVAL, 1994). Os progressos tecnológicos ocorridos ao longo do século XIX (litografia, fotografia) propiciaram o reconhecimento e a divulgação da diversidade das paisagens existentes na superfície terrestre, pela multiplicidade de pontos de vista sucessivos e do melhoramento substancial dos documentos iconográficos, como mapas e plantas cadastrais (CLAVAL, 2004, p. 17-18). A partir desse período, a paisagem se torna cartografável e, sua organização, mais reconhecível.

Com o surgimento do estudo da ecologia, no século XIX, e a partir dos trabalhos de Suess, a definir as noções de atmosfera, litosfera e hidrosfera, e de Ratzel, que delineia o campo da geografia humana, as paisagens deixam de ser quadros estáticos, sem vida, e passam a ser concebidas como interface entre a atmosfera, a litosfera, a hidrosfera e a ação humana, ou seja, como interface entre natureza e cultura. As relações complexas entre os seres humanos e os ambientes onde vivem passam, gradativamente, a ser incorporadas no estudo das paisagens. Claval sugere vir da abordagem de Ratzel a separação entre o domínio físico e o domínio cultural, que se estabelece mais fortemente no século XX (CLAVAL, 2004, p. 20-22) e, de certa forma, está associada às vertentes destacadas anteriormente (LEITE, 1992).

Saver reforça essa diferenciação, defendendo a divisão da paisagem em formas naturais e culturais como base de compreensão e revoluciona o estudo das paisagens ao propor um método morfológico de síntese, salientando a importância da identificação de tipos e padrões os quais as estruturam, das relações entre os elementos da forma que as compõem e da análise de seus conteúdos (SAUER, 1998). Nessa mesma direção, Troll percebe a paisagem como resultado de um processo de articulação entre os elementos os quais a constituem e indica que ela deve ser estudada no âmbito da ecologia da paisagem, no qual acontecem as interações entre os diferentes elementos. Esse autor também visualizava a paisagem como de ordem exclusivamente natural paisagem natural - ou de ordem humana - paisagem cultural (TROLL, 1950).

Entre as décadas de 1960 e 1970, os estudos da paisagem tomam novo impulso e traçam novos rumos. De um lado, estudos relacionados à ecologia e à ecologia da paisagem, como os elaborados por lan McHarg, Leopold, Wolman e Miller nos Estados Unidos (McHARG, 1969; - LEOPOLD; WOLMAN; MILLER, 1964), entre outros, 
começam a relacionar a ecologia ao planejamento e incorporar a idéia de processos ao estudo das paisagens, inspirados pelos trabalhos de Rachel Carson e Eugene Odum e pelo movimento de conscientização ambiental que emergia, na época, nos Estados Unidos e na Europa (CARSON, 1962; ODUM, 1963). Consolida-se, nessa época, a conscientização das profundas relações entre os aspectos físicos, biológicos e as realidades sociais, como coloca Bertrand (1971). Forman e Godron (FORMAN; GODRON; 1986, FORMAN, 1997) consolidam esse campo de estudos ao formular as bases metodológicas de análise em seus estudos relacionados à ecologia da paisagem, ciência que estuda as relações entre os padrões espaciais e os processos ecológicos em múltiplas escalas e níveis de organização.

\section{2 - Paisagem como essência simbólica, experimental e processual}

No campo perceptivo e simbólico, enfocando a questão da imagem transmitida pelas paisagens urbanas, Kevin Lynch (1960) muda o enfoque para a relação entre percepção, legibilidade, significado e identidade, indicando cinco tipos de elementos os quais a conformam: vias, limites, bairros, nós e elementos marcantes. Lynch observa que o ser humano utiliza "as sensações visuais de cor, forma, movimento ou polarização da luz, além de outros sentidos como o olfato, a audição, o tato" (LYNCH, 1960, p. 11 23), entre outros, como indicadores para se orientar, identificar e estruturar a imagem que faz das paisagens urbanas. Para o autor, nesse processo, cada indivíduo forma um quadro mental do mundo físico exterior, produto "tanto da sensação imediata quanto da lembrança de experiências passadas", usadas para "interpretar as informações" (LYNCH,1960, p. 3, 4).

Também dedicado à análise e avaliação das paisagens urbanas, Gordon Cullen busca entender como as paisagens urbanas suscitam "reações emocionais" nas pessoas, ao serem experimentadas, considerando três aspectos que concorrem para a apreensão das mesmas: a dimensão do visível, referente à visão serial, ao movimento; a dimensão local, referente à localização em um espaço determinado, recintos, unidades urbanas; e a dimensão relacionada ao conteúdo, formas de apropriação e interpretação (CULLEN, 1971, p. 10, 13).

Ao entender que todas as paisagens expressam a cultura de um determinado local e época específicos, por meio de representações individuais, Meinig indica que as paisagens acumulam essas representações e tornam-se extremamente complexas para serem entendidas em sua totalidade. O autor considera "todas as paisagens como simbólicas, como expressão dos valores culturais, do comportamento social e de ações individuais trabalhadas em localidades específicas por um período de tempo" (MEINIG, 1979 , p. 6). Para esse autor, a paisagem é uma acumulação de tempos e seu estudo pode ser entendido como história.

Yi Fu Tuan reforça o pensamento de Meining, ao sugerir que uma paisagem é uma percepção quase única, pessoal. "Paisagem é como uma imagem, uma construção da mente e do sentimento. Imagens de paisagens são potencialmente infinitas, ainda que 
elas pareçam ter semelhanças familiares." (TUAN, 1979, p. 89). Sopher acrescenta que a sensação de pertencimento é construída quando o indivíduo identifica e elege marcos, na paisagem, fixados na memória, aos quais sempre se remete para lembrar (MEINIG, 1979, p. 144), reforçando a relação entre paisagem e memória, aprofundada no campo da história cultural por Schama (SCHAMA, 1996).

Enfatizando a interação entre paisagem, tempo e espaço, Milton Santos concebe a paisagem como a expressão materializada do espaço, interpretando-a como forma, um dos elementos constituintes do espaço que, em um dado momento, expressam as heranças as quais representam as sucessivas relações entre o homem e a natureza. Nessa perspectiva, o autor diferencia paisagem de espaço: ao reunir objetos passados e presentes, a paisagem se torna "transtemporal" (SANTOS, 1997). Esse autor busca estabelecer a relação entre espaço e paisagem com base nas dimensões tempo e escala. Para Santos, uma paisagem é uma porção dinâmica do espaço. "A paisagem nada tem de fixo, de imóvel [...], uma paisagem representa diferentes momentos do desenvolvimento de uma sociedade. Para cada porção do espaço, essa acumulação é diferente: os objetos não mudam no mesmo lapso de tempo, na mesma velocidade ou na mesma direção." (SANTOS, 2004, p. 54)

De acordo com Suertegaray (2001), a paisagem pode ser concebida enquanto forma (configuração), funcionalidade (organização) e como um processo (dinâmica) de modelagem e remodelagem de formas conjugadas com a dinâmica social. Nesse sentido, a paisagem, mesmo onde persistem os elementos naturais, materializa as condições sociais inter-relacionadas à economia e à cultura. A paisagem não se encerra apenas no âmbito do visível nem é apenas, como apontou Gandy (2001), espelho, calidoscópio, palimpsesto, apesar de poder conter todos esses matizes. Ela constitui um sistema de interações entre natureza e cultura que expõe e é exposta a perspectivas filosóficas diversas, que se contradizem e complementam-se, como visto anteriormente.

$\mathrm{Na}$ atualidade, não basta descrever as paisagens, o desafio contemporâneo é procurar compreender as complexas relações que as conformam, movimentam, transformam e engendram identidades, conflitos, representações, apropriações, ideologias. Nesse sentido, no âmbito das discussões relacionadas aos sistemas de espaços livres, nossa reflexão pontua a paisagem como produto que incorpora os processos biofísicos e os processos sociais nela refletidos, em diversos tempos e escalas, e apresenta elementos de integração ou fragmentação territorial, criando e recriando formas, funções e fluxos, com funções ecológicas diversas, em estágios diferentes de intervenção humana.

Tanto em meio urbano como rural constituem sistemas interativos em que as lógicas de ocupação se rebatem sobre as lógicas do suporte natural, com maior ou menor intensidade, apresentando padrões perceptíveis, mais ou menos incorporados à estética e à imagem coletiva. Sujeito e objeto da relação entre a natureza e a ação humana, assume, em sua dimensão morfológica, o resultado das transformações funcionais, produtivas, e, portanto, econômicas, ao longo da história, e, em sua dimensão simbólica, os significantes e significados da relação ética e, portanto, estética, com os 
territórios sociais e culturais nos quais se insere (TÂNGARI, 1999). Por sua característica eminentemente dinâmica, não se restringe a um retrato estático de um único momento.

\section{4 - AMBIENTE}

A noção de ambiente talvez seja a que mais necessite ser considerada em seus múltiplos aspectos. Assim como território e paisagem, esse conceito se vincula ora a relações biofísicas, de cunho material e objetivo, ora a relações socioculturais e perceptivas, de cunho imaterial e subjetivo, e deve ser estudado a partir da interação desses dois campos de relações.

Historicamente, do ponto de vista biofísico, a noção de ambiente ou meio esteve, em um primeiro momento, vinculada à ecologia. Ao descrever os diversos ecossistemas e seus respectivos processos ecológicos, Odum (1963) observa a característica peculiar da relação entre a espécie humana e o ambiente, marcada pelo poder de controle e desenvolvimento de uma cultura adaptativa que difere em complexidade dos outros organismos encontrados na Terra. Para Odum, a humanidade, como todo ser vivo, busca dois itens básicos em seu ambiente: a produção e a proteção, e, sendo dotado de consciência, é capaz de apreciar seu valor estético. A geografia, inicialmente, não se referia ao termo ambiente, mas ao termo meio. Para Bertrand (1971), o conceito de meio está impregnado de um sentido ecológico, enquanto para Milton Santos (1997), o meio resulta de adaptações sucessivas do suporte físico ambiental às necessidades humanas. Em seu desenvolvimento histórico, no entanto, o conceito perdeu suas raízes, como de mediador entre um objeto e outro, e assumiu a concepção de campo de diversas manifestações relacionadas entre si como sistema.

Sob o viés sociocultural e perceptivo, diversos autores no campo da psicologia ambiental e social, da antropologia, da sociologia e da arquitetura discutem ambiente, destacando o papel da subjetividade e do caráter simbólico a ele associado.

A abordagem psicossocial, assim como a aborgagem da ecologia, considera o ambiente como um sistema de interdependências complexas. Conforme sublinhou Pagès (1974), a organização do ambiente ocorre a partir de influências advindas de imposições físicas e significações incorporadas e ganha sentido a partir de códigos interpretativos adquiridos, associados a conteúdos normativos e ideológicos.

O antropólogo Edward Hall (1977) sugere que a falta de sucesso de certos ambientes urbanos e arquitetônicos decorre de os mesmos serem criados sem serem consideradas as diferenças culturais dos diversos grupos sociais que os habitam. $\bigcirc$ autor destaca que os mecanismos culturais criam "filtros" perceptivos no processo de apreensão espacial. Fischer (1994), por sua vez, considera que as duas maneiras de conceber-se um ambiente, como um quadro funcional e como objeto de uma experiência vivida, complementam-se. Para esse autor, não se pode reduzir o ambiente a uma unidade independente da lógica social. Os laços tecidos entre a sociedade e o indivíduo moldam os ambientes humanos. A influência que o ambiente exerce sobre o comportamento humano é função dos valores nele inscritos, a atuarem como elementos normativos sobre os comportamentos e representações. 
Para Fischer (1994), a relação entre o ambiente e os comportamentos humanos é um processo contínuo, como um jogo, no qual, por um lado, o ambiente se reveste de atributos os quais exercem certas influências; por outro lado, é vivido por meio de usos e atribuições de sentido a refletirem nossa capacidade de agir sobre o ambiente, ao mesmo tempo em que a ele nos adaptamos. Os comportamentos e processos sociais são práticas determinadas pela natureza social, no interior da qual se organiza a experiência individual e coletiva.

Amos Rapoport (1990), apoiando-se na antropologia, na psicologia ambiental e na etnologia, observa como as pessoas reagem, percebem e sentem os ambientes. Para Rapoport, não se pode separar o significado da função, pois ele é sua parte mais importante. Elementos físicos de um ambiente não apenas tornam visíveis e estáveis as heranças e vivências culturais, eles também têm significados e codificam informações que podem ser decodificadas por quem os vivencia, afetando seu comportamento e o do grupo.

Esse autor ressalta a importância do ambiente, resultado de uma série de escolhas feitas ao longo do tempo, para a construção da memória de um grupo (RAPOPORT, 1990, p. 81). Assim, a "função mnemônica de um ambiente é equivalente para o grupo à memória e ao consenso". Para Rapoport, todos os ambientes possuem significados "não-verbais". $\bigcirc$ quanto as pessoas entendem um determinado ambiente está diretamente relacionado à sua capacidade de decodificá lo. A decodificação depende da capacidade de cada qual para entender os códigos (elementos) e a linguagem (fruto da ordenação desses códigos).

D'Agostini e Cunha (2007) ajudam a esclarecer a diferença entre meio e ambiente. Meio, segundo esses autores, é o lugar das relações as quais podem ou não adquirir significados. Ambiente é um estado de consciência que aflora a partir do significado dessas relações. "Ambientes são estados conscientes que seres vivem em salas, em ônibus, em florestas, em tribunais e em qualquer outro meio em que se encontrem." (D'AGOSTINI; CUNHA, 2007, p. 40, 41). É no âmbito da consciência que emerge a idéia de ambiente, a partir do significado das relações que nele são promovidas. $\bigcirc$ ambiente não se condiciona a partir da relação com um ser humano abstrato, mas com seres concretos e datados, que vivem coletivamente e estabelecem formas complexas de interagir com a natureza. $\bigcirc$ ambiente é dinâmico, incorpora um sistema de valores e transforma-se permanentemente. É o espaço experimentado, vivido, relacional.

A noção de ambiente não encerra apenas a dimensão natural, mas pressupõe uma visão integral decorrente da tomada de consciência da vida em sociedade, da relação entre as populações humanas e de suas interações com a natureza. $\bigcirc$ ambiente contém e envolve o ser humano como um dos elementos de transformação.

Suertegaray (2001) observa que, na perspectiva naturalista e naturalizante a permear, ainda, a ótica ambiental, o conceito de ambiente não colabora para o entendimento das tensões sociais sob as quais se originam os impactos. Na verdade, segundo a autora, o ser humano se inclui no ambiente não apenas como ser naturalizado, mas como um ser social, produto e produtor de várias tensões ambientais. 
Por outro lado, o ser humano não precisa ser sempre, necessariamente, o protagonista, o foco de atenção em todas as situações, em função de quem orbita o ambiente. Defendemos aqui a visão do ser humano como um dos elementos que interagem no meio biofísico e no meio cultural e simbólico, com outros elementos relacionados ao seu espaço de cognição, apreensão e vivência, produzindo, com maior ou menor intensidade, marcas indeléveis de sua interação e impactos decorrentes.

\section{5 - SISTEMA}

Conceito que fundamenta as pesquisas do grupo, a visão sistêmica constitui referência para as bases metodológicas de análise, a permearem nosso olhar sobre os objetos de estudo, em qualquer escala e definição territorial. Buscamos, nos autores abaixo, as definições que consideramos mais aplicáveis ao nosso trabalho.

De acordo com Ferrari (1997), sistema significa reunião, grupo, conjunto. Para esse autor, um sistema é composto pelas partes ou elementos componentes e as interligações ou interações entre elas. Essa interação ou interligação possui um objetivo, uma função.

Para D'Agostini e Cunha (2007), sistema é o conjunto de relações funcionais, estruturais e morfológicas ocorridas em um espaço e entre diferentes espaços. Esses autores também tratam sistema como conjunto, reunião de elementos em inter-relações, cuja organização contém um significado. Assim, em um sistema "estão sempre presentes a consciência que atribui significados às relações, as próprias relações e os elementos que se relacionam" (D'AGOSTINI; CUNHA, 2007, p. 55). Os sistemas podem ser formados não só por componentes concretos que se relacionam como também podem tratar de sistemas de relações: sistemas de valores, de leis, de interesses.

Segundo Capra (1997), o pensamento sistêmico opera com três elementos interdependentes: (1) padrão de organização - configuração dos componentes que condicionam as características essenciais de um sistema; (2) estrutura - inter-relação e incorporação do padrão de organização e das relações entre os componentes do sistema (sua forma, composição, ordenação) no espaço; (3) processo - atividade envolvida na organização do sistema que envolve a idéia de tempo, duração, ação continuada, a qual liga o padrão à estrutura.

A noção de "sistema" remete a um conjunto de elementos interconectados, de modo a formar um todo organizado ${ }^{4}$. É uma definição a permear várias disciplinas, como biologia, medicina, engenharia, informática e administração. Sistema significa combinar, ajustar, formar um conjunto. Um sistema consiste de componentes, entidades, partes ou elementos e as relações entre eles. A integração entre tais componentes pode se dar por fluxo de informações, matéria e energia.

De acordo com Morin (1990), o biólogo Ludwig Von Bertalanffy refinou o conceito de sistema em sua acepção contemporânea, ao cunhar a teoria dos sistemas na década de 1950. Essa teoria teve rebatimento nos mais diversos campos do conhecimento, da biologia à cibernética, e permite superar as crescentes dificuldades epistemológicas surgidas na contemporaneidade, com a potencialização da diversidade e da hiperfragmentação. 
Outra importante contribuição da teoria dos sistemas é a incorporação da noção de relatividade, fundada por Einstein, na compreensão de o comportamento de cada elemento de uma totalidade variar em função de sua relação com os demais, formando um tecido cujo estado é de permanente transformação. Essa formulação superou a rigidez do enfoque anterior concernente à estrutura.

A teoria dos sistemas tentou fornecer um modo de enxergar, pensar e agir sobre sistemas complexos, concebidos como corpos empíricos e/ou epistemológicos, formados por elementos em permanente transformação, resultante de relações as quais acontecem internamente (endógenas), que se estabelecem entre si, ou externas (exógenas), quando a totalidade interage com elementos não-pertencentes ao sistema.

De acordo com Morin, na teoria dos sistemas, o todo não se reduz à soma de suas partes constitutivas. A noção de sistema não é puramente formal, trata-se de uma noção ambígua, fluida. A teoria dos sistemas se situa em um nível transdisciplinar, permitindo, simultaneamente, conceber a unidade da ciência e a diferenciação dos campos disciplinares (MORIN, 1990, p. 29, 30).

Milton Santos (1988) também aponta a potencialidade do emprego da teoria dos sistemas para a compreensão do espaço urbano. Ao situar as dificuldades metodológicas em apreender-se o espaço em todas as suas dimensões, Santos define o espaço como uma totalidade, a exemplo da sociedade que the dá vida. Todavia, para fins de análise, sugere a possibilidade de dividi-lo em partes. Estas consistiriam, para o autor, de elementos em interação.

Ao articular a idéia de sistema à noção de estrutura espacial, as reflexões de Milton Santos direcionam a definição de espaço como sistema complexo. No que se refere ao comportamento evolutivo das estruturas e dos sistemas, o autor aponta três princípios: (1) o da ação externa, responsável pela evolução exógena do sistema; (2) o intercâmbio entre subsistemas (ou subestruturas), que permite falar de uma evolução interna do todo, uma evolução endógena; (3) uma evolução particular a cada parte ou elemento do sistema tomado isoladamente, evolução igualmente interna e endógena (SANTOS, 1988).

As metodologias vinculadas à ecologia encontram-se na base da teoria dos sistemas e das metodologias ambientais surgidas a partir da década de 1970. Nascidas em meio a discussões epistemológicas contemporâneas, com compromissos interdisciplinares, pelo menos no que se refere à biologia e à geografia e com maior distanciamento à sociologia e ao urbanismo, essas metodologias tentam traduzir a visão sistêmica no sentido de uma aferição dos impactos das ações e atividades humanas no espaço (ambiente). Nessa intenção, o ecossistema é dividido em três dimensões: meio físico, meio biótico e meio antrópico.

Cada parte do sistema pode ser considerada, isoladamente, também como um sistema, ou como um subsistema. Por outro lado, todo sistema pode também ser considerado como parte de um sistema mais amplo. Daí a importância da questão da escala. $O$ estudo das relações em um ambiente deve sempre estar integrado a uma compreensão da noção de escala espacial e da dimensão espaço-tempo. 
Do ponto de vista psicossocial, segundo Fischer, os ambientes humanos podem ser apreendidos em dois níveis: o macrossocial, que analisa o espaço no âmbito da sociedade global (região, cidade, bairro) e o microssocial, em escala de vizinhança, ou em ambientes circunscritos onde se desenrola a vivência cotidiana (locais de moradia, trabalho, lazer, etc.). Essas duas matrizes, a macro e a microssocial são interdependentes, encaixam-se e interconectam-se (FISCHER, 1994). Ainda segundo Fischer, a compreensão das relações no ambiente e com o ambiente ocorre em função da escala escolhida para o estudar.

O conceito de sistema não pretende encerrar a totalidade da realidade, mas apresentar uma esquematização que torne possível sua apreensão. A noção de sistema é fundamental para compreender as relações de interdependência, complementaridade e hierarquia entre os espaços livres, e encerra a visão que defendemos aqui.

Outros conceitos associados à noção de sistema e que permeiam nossas pesquisas se referem à fragmentação, integração e fronteira, aplicados à questão da paisagem, do território e do ambiente, e serão discutidos em uma futura publicação.

\section{6 - ESPAÇO}

Referimo-nos comumente ao "espaço" quando desejamos expressar uma visão científica, racional, da interação homem x mundo externo, que permite uma taxonomia composta por um leque de elementos referenciados ao mundo físico, incluindo os elementos morfológicos, como topografia, relevo, hidrografia e construções, e ao mundo social, que reflete os processos de interação entre a sociedade e sua localização.

Da mesma forma como as outras categorias conceituais abordadas, esse conceito permite amplos significados e interpretações, aplicáveis a diferentes campos de estudo, experimentação e intervenção. Para se compor um quadro referencial histórico, situamos o surgimento do conceito de espaço no primeiro sopro iluminista do Renascimento, para responder aos anseios de situar, localizar, apreender um sistema de referências locacionais, fundamental para permitir a simulação de situações territoriais. Para uma discussão com esse enfoque, vale lembrar a contribuição de Descartes. Este autor criou um sistema, uma grade de referências espaciais, nas quais Newton e os físicos se apoiaram para estudar o comportamento dos corpos. É importante observar que a preocupação, naquele momento, em relação ao que se denominava espaço não recaía sobre as características peculiares e diferenciadoras de cada segmento da natureza física, mas sobre uma "noção" de "mundo externo", percebida pelo sistema cognitivo humano na ordem do tempo.

Ao referir-se ao que é abstrato, o conceito de "espaço" remete à grade, à modelização, sendo capaz de servir como quadro de referência para lugares (concretos) inteiramente diversos em suas características intrínsecas e estar "associado a diferentes escalas (global, continental, regional, da cidade do bairro, da rua, da casa ou mesmo de um de seus cômodos)". Trata-se, assim, de base referencial preenchida com elementos diferenciados que a singularizam (HATSHORNE, 1939, p. 644). 
Na segunda metade do século XX, Haggett (1966) desenvolve uma metodologia de "análise locacional com base nos temas movimento, redes, nós, hierarquias e superfícies", posteriormente refinadas em uma abordagem sobre redes e o processo de regionalização. Sob influência do pragmatismo positivista, diversos modelos normativos sobre organização espacial, baseados em pressupostos caros ao pensamento burguês, foram elaborados.

Ao estudar a relação espaço-sociedade, David Harvey $(1969,1980)$ ressalta que as diferentes práticas humanas estabelecem conceitos de espaços diversos. Esse autor concebe o espaço em um contexto dialético, ao mesmo tempo absoluto (com existência material), relativo (como relação entre objetos) e relacional (espaço que contém e relaciona-se com os objetos). Harvey (2005) volta a estabelecer conexões entre espaço e tempo ao discutir a pós-modernidade e as lógicas de produção e reprodução do espaço, com base no sistema de produção capitalista.

Gomes (2002), fundamentado em uma perspectiva estruturalista, considera que, na geografia, o espaço e as condições espaciais constituem um componente ativo na dinâmica social, simultaneamente agente e testemunha de sua organização. Léfèbvre (1976, apud GOMES, 2002, p. 29), por sua vez, argumenta que o espaço "desempenha um papel e uma função decisivos na estruturação de uma totalidade, de uma lógica, de um sistema". Para o autor, o espaço não é apenas o ponto de partida (espaço absoluto), nem somente o ponto de chegada (espaço como produto social). Ele abarca essas concepções e ultrapassa-as enquanto "locus da reprodução das relações sociais de produção, isto é, da produção da sociedade" (LÉFÈBVRE,1976, apud GOMES, 2002, p. 29-34).

Nessa mesma linha de pensamento, Milton Santos considera espaço, formação socioeconômica e modos de produção como categorias interdependentes, referindose ao espaço como "fator social e não apenas como reflexo social" (SANTOS, 1988) e como uma "acumulação desigual de tempos" (SANTOS, 2004). O que implica considerar o espaço, assim como a paisagem, como herança residual, resultante dos processos sociais que definem condições específicas de localização (espaço-estrutura); de produção (espaço-função), de memória e significado (espaço-lugar).

Guattari e Deleuze (1992) aprofundam a reflexão sobre a subjetividade e sua aplicação na compreensão do espaço, mostrando que as estratégias construídas a partir do espaço acompanham processos muito sutis, que extrapolam elementos puramente locais, incluindo dimensões de incontáveis camadas de distanciamento, tendo em vista todos experimentarmos o "espaço" (no sentido da soberania - nação/estado/cidade/ etc.) em suas múltiplas dimensões de poder.

\subsection{Espaço-estrutura, espaço-função e espaço-lugar}

Em relação às condições de localização e produção, Milton Santos (1997) destaca que o espaço deve ser analisado a partir das categorias estrutura, processo, função e forma, e essas devem ser consideradas em suas relações dialéticas. Em outro momento de sua trajetória, esse autor interpreta espaço como um "sistema de objetos e um 
sistema de ações" formado por um conjunto indissociável, um quadro único no qual a história se dá; define espaço e tempo como categorias indissociáveis e trata o espaço como resultante da coexistência de tempos culturais diferentes, tempos tecnológicos diferentes, inserções diferentes do lugar no sistema ou na rede mundial globalizada, diferentes ritmos e processos de coexistências e novas possibilidades.

Segundo Milton Santos, quando a divisão do trabalho e as associações desiguais por ela ocasionadas estendem-se à escala do planeta, o mundo se torna o espaço global do capital. Desse modo, ao espaço é incorporada uma rede de relações sociais que o fazem ultrapassar as três dimensões da geometria clássica. Para Santos, o espaço não pode ser dissociado do homem - "o espaço humano compreende as áreas que permaneceram como espaço biológico, incluídas porém na rede das relações que, em nossos dias, já não são estritamente econômicas, senão também políticas etc., relações efetivas, mas também potenciais. Se existem espaços vazios, já não existem espaços neutros" (SANTOS, 2004, p. 23, 26).

O "espaço é a mais representativa das objetivações da sociedade, pois acumula, no decurso do tempo, as marcas das práxis acumuladas". Por exemplo, ao ser manipulado pelas normas de zoneamento, uso e ocupação do solo, ajuda a aprofundar as diferenças de classes (SANTOS, 2004, p. 32, 33).

O conceito de espaço é um conceito associado ao ideário moderno. Com a passagem da modernidade para a atualidade, sua utilização tornou-se restrita. Na linha do pensamento de Santos, o uso da palavra espaço em arquitetura deveria limitar-se às dimensões e características físicas do ambiente natural ou construído. Para fazer referência ao espaço habitado com seus significados simbólicos e seus valores culturais, a noção de ambiente, segundo esse autor, torna-se mais adequada. $O$ autor sugere, ainda, que a noção de "espaço" ganhou um uso crescentemente metafórico em diversas disciplinas, passando, com os progressos no conhecimento das galáxias, a ser, inclusive, associada ao espaço sideral interplanetário (SANTOS, 1997).

Em relação às condições de memória e significado, segundo Fischer, "na perspectiva psicossocial, o espaço é definido de várias maneiras: como um lugar, um ponto de referência definido" e delimitado, onde os objetos se situam, as atividades se desenrolam e os acontecimentos se produzem (FISCHER, 1994, p. 17). É também definido como meio, quadro objetivo sob influência de fatores sociais, que comporta significantes, estimula contatos e é condicionado por valores que nele se inscrevem.

Trazendo a discussão sobre o nosso foco de análise, a concepção de espaço ajudanos a pontuar, sobre uma base referencial, os recortes da dinâmica da paisagem em suas diversas escalas de análise, de apreensão e de intervenção, e as delimiłações de territórios, posto esses, ao se definirem por seus significados socioculturais, também se referirem diretamente a sistemas espaciais específicos.

\section{2 - Espaços livres}

Também o termo espaço livre é impregnado de múltiplos significados, sendo, geralmente, associados ao meio urbano no qual se definem pelo perfil de propriedade, 
acessibilidade ou uso, como públicos ou privados, minerais ou vegetados, associados às funções múltiplas de preservação, recreação, convívio, circulação (MERLIN; CHOAY, 1988 - RONCAYOLO, 2002).

Miranda Magnoli (1982) define os espaços livres urbanos como os espaços livres de edificação: quintais, jardins públicos ou privados, ruas, avenidas, praças, parques, rios, florestas, mangues e praias urbanas, ou simples vazios urbanos. Kevin Lynch (1984) se refere a espaços abertos em contraposição aos espaços fechados das edificações. Segundo Silvio Macedo et al (2007), enquanto sistema, os espaços livres urbanos apresentam relações de conectividade e complementaridade, mesmo que estes não tenham sido planejados ou implantados como tal.

Esses espaços formam, conforme sugere Catharina Lima, um "tecido pervasivo", a permear todo o espaço urbano, justapondo-se ao sistema de objetos edificados e seu correspondente sistema de ações. São eles que, quase sempre, constituem o maior porcentual do solo das cidades brasileiras, mesmo entre as mais populosas (LIMA, 1996).

Gilles Clément (2004) associa a essa gama de espaços não-ocupados, vazios ou abandonados, a característica de compor um mosaico rico de manifestações de diversidade biofísica e cultural, tanto em meio rural como urbano.

Os espaços livres urbanos constituem um sistema complexo, inter-relacionado com outros sistemas urbanos que podem se justapor ao sistema de espaços livres (sistema de objetos edificados e seu correspondente sistema de ações) ou se sobrepor, total ou parcialmente, enquanto sistemas de ações. Entre seus múltiplos papéis, por vezes sobrepostos, estão a circulação e a drenagem urbanas, atividades de lazer, conforto, preservação, conservação, requalificação ambiental e convívio social. O sistema de espaços livres de cada recorte espacial, tanto urbano como rural pode apresentar um maior ou menor grau de planejamento e projeto, um maior ou menor interesse da gestão pública em um ou em outro subsistema a ele relacionado.

Ao estudarmos espaços construídos e espaços livres de ocupação e edificação, espaços públicos e espaços privados, espaços individuais e espaços coletivos, espaços de recreação e circulação, espaços abertos e espaços fechados, dentre as diversas categorias de análise aplicáveis à nossa pesquisa, estaremos sempre associando seus significados quanto à estrutura, função e lugar a uma base física, visando referenciar, quantificar, qualificar e definir atributos de valoração social, ambiental e cultural a eles associados.

\section{CONSIDERAÇÕES FINAIS}

Nosso recorte buscou relacionar criticamente os significados dos conceitos território, paisagem, ambiente, sistema e espaço, buscando oferecer uma gama diversificada, mas não estanque, de abordagens e definições estabelecidas por diversos autores e campos de conhecimento. $\bigcirc$ processo de transformação dos conceitos, exposto neste artigo, permite perceber leituras relacionadas às perspectivas filosóficas que thes deram origem. As definições enunciadas ora se complementam ora se justapõem, ou 
mesmo se contrapõem sob alguns aspectos. Ao reuni-las neste artigo, procuramos ressaltar abrangências, interseções e divergências, sem a preocupação de esgotar o tema ou estabelecer definições de sentido único. Os conceitos descritos ao longo do trabalho foram considerados como instrumentos de leitura para organizar e estruturar os vários significados dos sistemas de espaços livres nos contextos a serem analisados pelo grupo de pesquisa.

Esperamos que este texto auxilie na aproximação dos diversos campos disciplinares que trabalham os conceitos abordados, com vistas à construção de um arcabouço teórico transdiciplinar, aplicável ao objeto a que nos propusemos a estudar, e também possa servir de instrumentação a futuras pesquisas e estudos relacionados.

\section{Notas}

(1) O conceito é uma "representação mental de um objeto abstrato ou concreto, que se mostra como um instrumento fundamental do pensamento em sua tarefa de identificar, descrever e classificar os diferentes elementos e aspectos da realidade" (HOUAISS, 2001).

(2) Magnoli distingue algumas situações, em relação aos níveis de intervenção antrópica, que aumentam a amplitude da definição de "paisagem": paisagens encontradas em seu hábitat natural, com pouca ou nenhuma intervenção humana (savanas, desertos, florestas); paisagens preservadas (reservas, parques nacionais, estações ecológicas), paisagens em áreas de industrialização intensa (parques siderúrgicos, complexos industriais), paisagens funcionais com baixo índice de ocupação humana (barragens, áreas de mineração, fazendas de produção industrial) e paisagens com ocupação humana intensiva, correspondendo a todos os núcleos e aglomerações urbanas (MAGNOLI, 2006).

(3) Essa dimensão, também descrita por Magnoli (2006, p. 118), traduz a interação entre a "lógica própria dos processos do suporte (sistemas geológico e climático) a lógica própria dos processos sociais e culturais (sistema antrópico)".

(4) Disponível em: <http://pt.wikipedia.org/wiki/Sistema>. Acesso em: 06 abr. 2008.

\section{Bibliografia}

AB'SABER, Aziz. Os domínios de natureza no Brasil - Potencialidades paisagísticas. São Paulo: Ateliê Editorial, 2003.

ALTMAN, I. The environment and social behavior privacy: Personal space, territories, crowding. Monterey: Brooks/ Cole, 1975.

BERTRAND, G. Paisagem e geografia física global. Tradução de O. Cruz. Caderno de Ciências da Terra, São Paulo: Instituto de Geografia-USP, 1971.

CAPRA, Fritjof. A teia da vida. São Paulo: Cultrix, 1997.

CARLOS, A. F. A cidade. O homem e a cidade. A cidade e o cidadão. De quem é o solo urbano? São Paulo: Contexto, 1994.

CARSON, Rachel. Silent spring. Boston: Houghton Mifflin, 1962.

CLAVAL, Paul. L'analyse des paysages. Geographie et Cultures, Paris, v. 4, n. 13, p. 55-74, 1994.

O território na transição da pós-modernidade. Geographia - Revista da Pós-graduação em Geografia da UFF. Niterói: UFF, p. 7-27, 1999.

. A paisagem dos geógrafos. In: CORRÊA, Roberto Lobato; ROSENDAHL, Zeny (Orgs.). Paisagem, textos e identidade. Rio de Janeiro: EDUERJ, 2004. 
CLÉMENT, Gilles. Manifeste du tiers paysage. Paris: Éditions Sujet-Objet, 2004.

CONSELHO DA EUROPA. Convenção Européia da Paisagem. Florença: Conselho da Europa, 2000. Disponível em: http://www.apap.pt/Anexos/paisagem 1.pdf e http://www.gddc.pt/siii/docs/dec4-2005.pdf.

CORRÊA, Roberto Lobato. O espaço urbano. São Paulo: Ática, 1989.

. Espaço: Um conceito-chave da geografia. In: CASTRO, Iná Elias de; GOMES, Paulo Cesar da Costa;

CORRÊA, Roberto Lobato (Orgs.). Geografia - Conceitos e temas. Rio de Janeiro: Bertrand Brasil, 1995.

Paisagem, textos e identidade. Rio de Janeiro: EDUERJ, 2004.

. ROSENDAHL, Zeny (Orgs.). Paisagem, tempo e cultura. Rio de Janeiro: EDUERJ, 1998.

COSGROVE, Denis. Social formation and symbolic landscape. Madison: University of Wisconsin Press, 1998.

. Geography is everywhere: Culture and simbolism in human landscapes. In: GREGORY, D;

WALFORD, R. Horizons in human geography. Londres: Macmillan, 1989.

. A geografia está em toda a parte: Cultura e simbolismo nas paisagens humanas. In: CORREA, Roberto Lobato; ROSENDAHL, Zeny (Orgs.). Paisagem, tempo e cultura. Rio de Janeiro: EDUERJ, 1998.

CULLEN, Gordon. Paisagem urbana (Townscape). Lisboa: Edições 70, 1983.

D'AGOStINI, Luiz Renato; CUNHA, Ana Paula Pereira. Ambiente. Rio de Janeiro: Garamond, 2007.

DELEUZE, G.; GUATTARI, F. Heterogênese. In: DELEUZE, G.; GUATTARI, F. Caosmose: Um novo paradigma estético. Rio de Janeiro: Editora 34, 1992.

FERRARI, Célson. Planejamento municipal integrado. São Paulo: Livraria Pioneira Editora, 1997.

FORMAN, Richard. Land mosaics - The ecology of landscapes and regions. Cambridge: University Press, 1997.

FORMAN, Richard; GODRON, Michel. Landscape ecology. Nova York: John Wiley \& Sons, 1986.

FOUCAULT, Michel. Microfísica do poder. São Paulo: Graal, 1979.

FISCHER, Gustave-N. Psicologia social do ambiente. Lisboa: Instituto Piaget, 1994.

GANDY, Matthew. Paysage, esthétiques et ideologies. Geographie et Cultures, Paris, n. 39, 2001.

GENRO FILHO, A. Marxismo filosofia profana. Porto Alegre: Tchê! Editora, 1986.

GOMES, Paulo Cesar da Costa. A condição urbana: Ensaios de geopolítica da cidade. Rio de Janeiro: Bertrand Brasil, 2002.

HARTSHORNE, R. The nature of geography. Lancaster: Association of American Geographers, 1939.

HAGGETT, P. Location analysis in human geography. Nova York: Saint Martin's Press, 1966.

HALL, Edward. A dimensão oculta. Rio de Janeiro: Francisco Alves, 1977.

HARVEY, David. Explanation in geography. Londres: Edward Arnold, 1969.

. A justiça social e a cidade. São Paulo: Hucitec, 1980.

. A produção capitalista do espaço. São Paulo: Annablume, 2005.

HIJIOKA, Akemi et al. Espaços livres e espacialidades da esfera de vida pública: Uma proposição conceitual para o sistema de espaços livres urbanos no país. Paisagem e Ambiente: Ensaios, São Paulo: FAUUSP, n. 23, 2007.

HOUAISS, A .; VILLAR, M. S. Dicionário Houaiss da língua portuguesa. Rio de Janeiro: Objetiva, 2001.

LEFÈBVRE, Henri. La production de l'éspace. Paris: Anthropos, 1976.

LEITE, Maria Angela Faggin P. A paisagem, a natureza e a natureza das atitudes do homem. Paisagem e Ambiente: Ensaios, São Paulo: FAUUSP, n. 4, p. 45-66, 1992.

LEOPOLD, L.; WOLMAN, M.; MILLER, J. Fluvial processes in geomorphology. São Francisco: W. H. Freeman and Co., 1964.

LEWIN, K. Psychologie dynamique. Paris: P. U. F., 1972.

LYNCH, Kevin. Image of the city. Cambridge: MIT Press, 1960.

LIMA, Catharina Pinheiro Cordeiro dos Santos. A natureza na cidade, a natureza da cidade. 1996. Tese (Doutorado) - Faculdade de Arquitetura e Urbanismo, Universidade de São Paulo, São Paulo, 1996.

MACEDO. Silvio S. Quadro do paisagismo no Brasil. São Paulo: Quapá, 1999. 
Mônica Bahia Schlee, Maria Julieta Nunes, Andrea Queiroz Rego, Paulo Rheingantz, Maria Ângela Dias, Vera Regina Tângari

MAGNOLI, Miranda M. E. M. Espaços livres e urbanização: Uma introdução a aspectos da paisagem metropolitana. 1982. Tese (Livre-docência) - Faculdade de Arquitetura e Urbanismo, Universidade de São Paulo, São Paulo, 1982. p. 177-200, 2006.

Espaço livre - Objeto de trabalho. Paisagem e Ambiente: Ensaios, São Paulo: FAUUSP, n. 21, Em busca de outros espaços livres de edificação. Paisagem e Ambiente: Ensaios, São Paulo: FAUUSP, $\mathrm{n}$. 21, p. 143-173, 2006.

MACEDO, Silvio S.; CUSTÓDIO, Vanderli; GALLENDER, Fanny; QUEIROGA, Eugênio; ROBBA, Fabio. Os sistemas de espaços livres e a constituição da esfera pública contenporânea no Brasil . In: TERRA, Carlos; ANDRADE, Rubens. Paisagens culturais, Rio de Janeiro: EBA-UFRJ, v. 3, p. 286-297, 2007. (Coleção).

McHARG, lan. Design with nature. Nova York: Wiley, 1992.

MEINIG, D. W. (Org.) The interpretation of ordinary landscapes - Geographical essays. Oxford: University Press, 1979.

MERLIN, Pierre; CHOAY, Françoise. Dictionnaire de lúrbanisme et de l'aménagement. Paris: Presses Universitaire de France, 1988.

MORIN, Edgard. Introdução ao pensamento complexo. 2. ed. Lisboa: Divisão Editorial Instituto Piaget, 1990. (Coleção Epistemologia e sociedade).

ODUM, Eugene. Ecology. Nova York: Holt, Rinehart and Winston, 1963.

PAGÈS, R. La psychologie écologique: Applications validatricesou analyse de mécanismes? XVII CONGRESSO INTERNACIONAL DE PSICOLOGIA APLICADA, 1, 1974, Paris. Anais... Paris: Institut de L'Environnement, 1974.

RAFFESTIN, C. Por uma geografia do poder. São Paulo: Ática, 1993.

RAPOPORT, Amos. The meaning of the build environment - A nonverbal communication approach. Tucson: The University of Arizona Press. 1990.

RATZEL, Friedrich. Politische geographie. Osnabrúck: Otto Zeller Verlag, 1974.

El territorio, la sociedad y el estado. In: MENDOZA, J. G. ; JIMENEZ, J. M.; CONTERO, N. (Org.) El pensamiento geográfico. Estudio interpretativo y antologia de textos (De Humboldt a las tendências atuales). Madri: Alianza Editorial, 1982.

RONCAYOLO, Marcel. Lectures de villes - Formes et temps. Marselha: Éditions Parenthèses, 2002.

SANTOS, Milton. Espaço e método. São Paulo: Nobel, 1988.

A natureza do espaço. Técnica e tempo. Razão e emoção. São Paulo: Hucitec, 1997.

O meio técnico-científico-informacional, as redes e a cidade global. Folha de São Paulo, São Paulo, 13 abr. 1997. Caderno MAIS.

O país distorcido. O Brasil, a globalização e a cidadania. São Paulo: Publifolha, 2002.

Pensando o espaço do homem. São Paulo: Edusp, 2004

SAUER, Carl. The morphology of landscape. Publications in geography, Califórnia: University of California, v. 2, n. 2, p. 19-54, 1925.

A morfologia da paisagem. In: CORRÊA, Roberto Lobato; ROSENDAHL, Zeny (Orgs.). Paisagem, tempo e cultura. Rio de Janeiro: EDUERJ, 1998.

SCHAMA, Simon. Paisagem e memória. São Paulo: Cia. das Letras/Ed. Schwarcz, 1996.

SOPHER, David. The landscape of home: Mith, experience, social meaning. In: MEINIG, D. W. (Org.) The interpretation of ordinary landscapes - Geographical essays. Oxford: University Press, 1979.

SOUZA, Marcelo; LOPES, José. O território; sobre espaço e poder, autonomia e desenvolvimento. In: CASTRO, Iná. Elias de; GOMES, Paulo Cesar da Costa; CORRÊA, Roberto Lobato (Orgs.). Geografia conceitos e temas. Rio de Janeiro: Bertrand Brasil, 1995.

SUERTEGARAY, Dirce Maria Antunes. Espaço geográfico uno e múltiplo. Scripta Nova. Revista Electrónica de Geografía y Ciencias Sociales, Barcelona: Universidade de Barcelona. Disponível em: <http://www.ub.es/geocrit/sn-93. htm >. Acesso em: 17 dez. 2007.

TÂNGARI, Vera. Um outro lado do Rio. 1999. Tese (Doutorado) - Faculdade de Arquitetura e Urbanismo, Universidade de São Paulo, São Paulo, 1999.

TROLL, Carl. Die geographische Landschaft und ihre Erforschung. Heidelberg: Studium Generale, n. 3, p. 163-181, 1950. 
TUAN, Yi Fu. Thought the landscape: The eye and the mind's eye. In: MEINIG, D. W. (Org.) The interpretation of ordinary landscapes - Geographical essays. Oxford: University Press, 1979.

WIKIPÉDIA, Enciclopédia virtual. Disponível em: <http://pt.wikipedia.org/wiki/Sistema>.

\section{Observações}

Esse artigo foi elaborado pelos autores com base na produção do grupo de pesquisa Grupo SEL-RJ. Este tem como foco principal o sistema de espaços livres e sua relação com o planejamento e o desenho urbanos e a configuração e dinâmica da paisagem no estado do Rio de Janeiro. Esta pesquisa se insere no âmbito do Programa de PósGraduação em Arquitetura da Universidade Federal do Rio de Janeiro (PROARQ-FAUUFRJ), sob a coordenação da professora doutora Vera Regina Tângari. O grupo é composto pelos seguintes professores/pesquisadores: Paulo Afonso Rheingantz, Maria Angela Dias, Cristiane Rose Duarte, Maria Julieta Nunes, Andrea Queiroz Rego, Jonathas Magalhães Pereira da Silva, Rita Montezuma (doutores); Mônica Bahia Schlee, Rubens Andrade (doutorandos); Bethânia Azevedo, Rogerio Cardeman, Elaine Moreira (mestrandos); e pesquisadores associados: Larry Herzog, Denise Alcântara, Mariana Vieira, Flavia Teixeira Braga, Flavia Amorim e Magali Lafond. Conta ainda com a participação dos estudantes de graduação em arquitetura: Isabelle Falchetti, Cauê Capille, Natalia Parahyba e Raquel Cordeiro.

Apoio: CNPq (Edital Ciências Humanas, Sociais e Sociais Aplicadas); FAPERJ (Programas: Jovem Cientista do Nosso Estado; Estímulo à Produção e Divulgação Científica e Tecnológica; Iniciação Científica). 


\section{NORMAS PARA PUBLICAÇÃO - REVISTA PAISAGEM E AMBIENTE: ENSAIOS}

10 Conselho Editorial da revista Paisagem e Ambiente: Ensaios decidirá quais artigos, ensaios, conferências, debates, resenhas, relatos de experiências e notas técnicas terão a possibilidade de publicação, considerando-se para tanto a consistência teórica e a pertinência do tema diante da linha editorial.

2. Apresentação dos trabalhos:

Em mídia eletrônica (CD, DVD), utilizando o processador de texto WORD 6.0 ou superior. Deverá conter entre 21.600 a 43.200 caracteres, incluindo 0 resumo, 0 abstract e a introdução. Deverão ser entregues com o CD/DVD, três cópias impressas do arquivo.

0 resumo e 0 abstract não deverão ultrapassar 2.800 caracteres.

3. Os títulos e os subtítulos deverão aparecer em maiúsculas, pois é importante que no original fique clara sua natureza. Também deverão ser concisos e explícitos quanto ao conteúdo tratado. Deverão ser apresentadas, no mínimo, 5 palavras-chave (unitermos).

As contribuições deverão ser acompanhadas da versão em língua inglesa do título, subtítulo, resumo e palavras-chave.

4. Logo após o título, devem constar o nome do autor, sua qualificação, procedência e endereço postal e/ou eletrônico.

5. As notas e referências bibliográficas deverão ser agrupadas no final do texto e devidamente referenciadas, de acordo com as normas NBR 6023 e NBR 10520, da ABNT.

As notas e referências deverão seguir os seguintes padrões:

5.1. Artigos e capítulos de livros

Colocar a referência bibliográfica nesta ordem: autor, título do artigo/capítulo, nome do autor do livro, título do livro (em itálico), subtíiulo (sem itálico), edição, local de publicação (cidade), editora, volume, data de publicação, série ou coleção.

Exemplos

- autor do capítulo e do livro

MACEDO, Silvio Soares. Ecletismo. Quadro do paisagismo no Brasil. São Paulo: Edição do autor, 1999. (Coleção Quapá).

- autor somente do artigo ou capítulo

MACEDO, Silvio Soares. Robero Burle Marx and the founding of Modern Brazilian Landscape Architecture. In: VACCARINO, R. (E.) Roberto Burle Marx. Landscapes reflected. Nova York: Princenton Architectural Press, 2000.

5.2. Artigos publicados em periódicos

Indicar 0 autor do artigo, título do artigo, subtítulo do artigo, título da revista (em itálico), local de publicação (cidade), título do fascículo, se houver (suplemento ou número especial), volume, número, páginas (inicial e final), mês e ano.

Exemplo

PELLEGRIN0, Paulo Renato Mesquita. Pode-se planejar a paisagem? Paisagem e Ambiente: Ensaios, São Paulo, n. 13, p.159-179, 2000.

5.3. Citações no corpo do texto - Referências Bibliográficas

As citações, quando forem literais, devem ser precisas, grafadas em itálico e entre

"aspas". No corpo do texto devem constar o sobrenome do autor, data e páginas da publicação. Ex.: (LEITE, 1994, p.86)

Nas Referências Bibliográficas, o sobrenome do autor citado deve ser posto em ordem alfabética (em maiúsculas), prenome, título do livro (em

itálico), subtítulo (sem itálico), edição, local de edição (cidade), editora, volume, ano de publicação, série ou coleção (entre parênteses).

Exemplo

LEITE, Maria Angela Faggin Pereira. Destruição ou desconstrução? Questões da paisagem e tendências de regionalização. São Paulo: Hucitec, 1994.

5.4. Dissertações e Teses

As referências de tese de doutorado ou dissertação de mestrado devem conter: nome do autor, título (em itálico), subtítulo (sem itálico), data, número de páginas ou volume, categoria (grau), identificação da instituição, local, data de publicação.

Exemplo

QUEIROGA, Eugenio Fernandes. A megalópole e a praça: 0 espaço entre a razão de dominaçãa e a ação comunicativa. 2001. 351 p. Tese (Doutorado) - Faculdade de Arquitetura e Urbanismo, Universidade de São Paulo, São Paulo, 2001.

6. As ilustrações deverão ser entregues em folhas separadas com as devidas indicações de créditos e legendas, devidamente referenciadas no texto. Os desenhos deverão ser entregues em arte-final, preferencialmente a nanquim sobre papel schoeller. No caso de imagens, deverão ser entregues os originais, para serem escaneados no Laboratório de Programação Gráfica.

Em caso de arquivo eletrônico, a imagem deverá ter 300 d.p.i., no tamanho $12 \times 15$ cm, em RGB. As imagens não serão recebidas por correio eletrônico. Será permitida a inclusão de ilustrações que poderão ser impressas em cores, dependendo da disponibilidade de recursos para a impressão. As ilustrações (fotos, desenhos, esquemas e croquis) poderão ocupar um número equivalente de páginas daquelas ocupadas pelo texto.

7. Não serão aceitas reproduções de imagens publicadas em livros, revistas ou periódicos, sem a expressa autorização do(s) autor(es) das mesmas.

8. Após o ato de entrega, as condições dos originais serão analisadas criteriosamente. Os trabalhos que estiverem em desacordo com os padrões aqui descritos serão devolvidos em seguida para que se providencie sua regularização.

9. Os textos assinados serão de inteira responsabilidade dos autores e não haverá alteração de seu conteúdo sem prévia autorização.

10. Os autores receberão gratuitamente três exemplares do fascículo no qual constar publicada a sua contribuição. 